\title{
Total extraperitoneal (TEP) versus laparoscopic transabdominal preperitoneal (TAPP) hernioplasty: systematic review and trial sequential analysis of randomized controlled trials
}

\author{
Alberto Aiolfi ${ }^{1}$ - Marta Cavalli ${ }^{2}$. Simona Del Ferraro ${ }^{2} \cdot$ Livia Manfredini $^{2} \cdot$ Francesca Lombardo $^{1}$. \\ Gianluca Bonitta ${ }^{1} \cdot$ Piero Giovanni Bruni ${ }^{2}$. Valerio Panizzo ${ }^{1} \cdot$ Giampiero Campanelli $^{2}$. Davide Bona ${ }^{1}$
}

Received: 6 February 2021 / Accepted: 29 March 2021 / Published online: 13 April 2021

(c) The Author(s) 2021

\begin{abstract}
Purpose To examine the updated evidence on safety, effectiveness, and outcomes of the totally extraperitoneal (TEP) versus the laparoscopic transabdominal preperitoneal (TAPP) repair and to explore the timely tendency variations favoring one treatment over another.

Methods Systematic review and trial sequential analysis (TSA) of randomized controlled trials (RCTs). MEDLINE, Scopus, Web of Science, Cochrane Central Library, and ClinicalTrials.gov were consulted. Risk Ratio (RR), weighted mean difference (WMD), and 95\% confidence intervals (CI) were used as pooled effect size measures.

Results Fifteen RCTs were included (1359 patients). Of these, 702 (51.6\%) underwent TAPP and 657 (48.4\%) TEP repair. The age of the patients ranged from 18 to 92 years and $87.9 \%$ were males. The estimated pooled RR for hernia recurrence $(\mathrm{RR}=0.83 ; 95 \% \mathrm{CI} 0.35-1.96)$ and chronic pain $(\mathrm{RR}=1.51 ; 95 \% \mathrm{CI} 0.54-4.22)$ were similar for TEP vs. TAPP. The TSA shows a cumulative $z$-curve without crossing the monitoring boundaries line $(Z=1.96)$, thus supporting true negative results while the information size was calculated as adequate for both outcomes. No significant differences were found in term of early postoperative pain, operative time, wound-related complications, hospital length of stay, return to work/daily activities, and costs.

Conclusions TEP and TAPP repair seems comparable in terms of postoperative hernia recurrence and chronic pain. The cumulative evidence and information size are sufficient to provide a conclusive evidence on recurrence and chronic pain. Similar trials or meta-analyses seem unlikely to show diverse results and should be discouraged.
\end{abstract}

Keywords Inguinal hernia $\cdot$ Laparoscopic transabdominal preperitoneal repair (TAPP) - Totally extraperitoneal repair (TEP) $\cdot$ Recurrence $\cdot$ Chronic pain $\cdot$ Trial sequential analysis

Alberto Aiolfi

alberto.aiolfi86@gmail.com

Marta Cavalli

marta_cavalli@hotmail.it

Simona Del Ferraro

s.delferraro@gmail.com

Livia Manfredini

manfredini.livia@gmail.com

Francesca Lombardo

francesca.lombardo89@gmail.com

Gianluca Bonitta

bbonit@icloud.com

Piero Giovanni Bruni

pierogiovanni.bruni@gmail.com
Valerio Panizzo

panizzo.valerio@gmail.com

Giampiero Campanelli

giampiero.campanelli@grupposandonato.it

Davide Bona

davide.bona@unimi.it

1 Division of General Surgery, Department of Biomedical Science for Health, Istitituto Clinico Sant'Ambrogio, University of Milan, Milan, Italy

2 Department of Surgery, Istituto Clinico Sant'Ambrogio, University of Insubria, Milan, Italy 


\section{Introduction}

Worldwide, more than 20 million patients suffer from inguinal hernia and undergo elective repair yearly [1, 2]. The Lichtenstein tension-free repair is the most commonly performed procedure with a low recurrence and complication rate [3]. Since the first description in the early ' 90 s and because of the advent of innovative surgical platforms, the surgical technique evolved and the laparoscopic transabdominal preperitoneal (TAPP) repair and the totally extraperitoneal repair (TEP) emerged [4-10].

Compared to the Lichtenstein technique, minimally invasive approaches seem associated with a reduced risk of wound-related complication, early postoperative pain, return to work/activities, and chronic pain compared to the open approach [11]. The advantage of TEP repair is the nonviolation of the peritoneal cavity with the procedure totally performed in the preperitoneal space [12]. By contrast, TAPP repair requires peritoneal "violation" with the advantage of no technical/space constraints and the opportunity to provide a panoramic view of the myopectineal orifice with detection of unsuspected contralateral hernia when an adequate dissection of the preperitoneal space is achieved [13, 14]. Previous studies and meta-analysis described conflicting results for the direct comparison TEP vs. TAPP, while a robust indication of the best minimally invasive surgical option for the treatment of inguinal hernia remains unsettled [15-21].

The purpose of the present systematic review is to deeply assess the TEP vs. TAPP comparison for inguinal hernia repair in the setting of randomized controlled trials (RCT) and to perform a trial sequential analysis (TSA) to investigate if the required information size has been reached with conclusive evidence or oppositely if further trials and investigations are needed.

\section{Materials and methods}

A systematic review was performed according to the guidelines from the preferred reporting items for systematic reviews (PRISMA) [22]. Institutional review board approval was not required. MEDLINE, Scopus, Web of Science, Cochrane Central Library, and ClinicalTrials.gov were used [23]. The last date of search was the November 30th, 2020. A combination of the following MeSH terms (Medical Subject Headings) were used: "Inguinal", "Groin", "Hernia", "Herniorrhaphy", "Mesh", "Prosthetic material", "Laparoscopic", "Endoscopic", "Transabdominal Preperitoneal" (TAPP), and "Totally Extraperitoneal" (TEP). Titles, abstracts, and references were evaluated. The PROSPERO study protocol was CRD42018091308.

\section{Inclusion and exclusion criteria}

Inclusion criteria were: (a) RCT comparing surgical outcomes for elective inguinal hernia mesh repair for TAPP and TEP; (b) articles written in English; (c) when two or more papers were published by the same institution, study group, or used the same data-set, articles with the longest followup or the largest sample size; (d) in case of duplicate studies with accumulating numbers of patients, only the most complete reports were included for quantitative analysis. Exclusion criteria include: (a) observational non-RCT studies (b) non-English written; (c) non-clearly described methodology and technique; (d) single-arm studies; (e) studies with $\leq 15$ patients per treatment arm.

\section{Data extraction}

Extracted data include: author, year of publication, country, study design, number of patients, sex, age, body mass index (BMI), surgical approach, postoperative outcomes, quality of life, return to work/daily activities (days), cosmetic results, and costs (\$). All data were independently computed by three investigators (SDF, LM, AA) and compared at the end of the reviewing process. A fourth authors (GC) reviewed the database and clarified discrepancies.

\section{Quality assessment}

Three authors (AA, SDF, LM) assessed the methodologic quality of the selected trials using the Cochrane risk of bias tool [24]. This tool evaluates the following criteria: (1) method of randomization; (2) allocation concealment; (3) baseline comparability of study groups; and (4) blinding and completeness of follow-up. Trials were graded as having low (green circle), high (red circle), or unclear (yellow circle) risk of bias.

\section{Outcomes of interest}

Primary outcomes include: chronic pain defined as as groin pain lasting for at least 3 months after the index procedure and hernia recurrence. Secondary outcomes include: early postoperative pain assessed with the Visual Analog Scale (VAS), wound-related complications (haematoma, seroma, and wound infection), operative time (minutes), hospital length of stay (HLOS), patients'-reported outcomes (quality of life and cosmetics), and costs (\$). Outcomes were collected according to articles reporting. Haematoma was defined as any clinically diagnosed surgical site or scrotal hematoma. Seroma was defined clinically as a localized fluid filled sac that appeared on the operative site. Wound infection was defined as the presence of clinically 
diagnosed erythema, or purulent secretion or purulent secretion with fever. Hernia recurrence was defined clinically in all included RCT's.

\section{Statistical analysis}

The results of the systematic review were qualitatively summarized into frequentist study level random-effect meta-analysis of pooled risk ratio (RR) and standardized mean difference (SMD). An inverse-variance method and DerSimonian-Laird estimator for the variance of the true effect size $\left(\tau^{2}\right)$ was performed [25]. Heterogeneity among studies was evaluated by the $I^{2}$ index and Cochran's $Q$ test [26]. Statistical heterogeneity was considered low, moderate, and high for $I^{2}$ values of 25,50 , and $75 \%$, respectively, and significant when $p<0.10[27,28]$. The Wald-type $95 \%$ confidence interval (CI) was computed for pooled measurements; otherwise, the $95 \%$ CI for the $I^{2}$ index was calculated according to Higgins and Thompson [29]. The prediction interval for the treatment effect of a new study was calculated according to Borestein [26]. As the sample size was not the same in all studies, we performed a sensitivity analysis by excluding one study each time and rerunning the analysis to verify the robustness of the overall results. A two-sided $p$ value was considered statistically significant when $p<0.05$. All analyses and figures were carried out using the $R$ software program, version 3.2.2 [30].

A TSA was performed to assess the possibility of type one error and to compute information size [31]. The Lan-DeMets approach was used to construct monitoring boundaries and to set adjusted thresholds for statistical significance. The information size was calculated at $\alpha=0.05$ and $\beta=0.2$, with a risk ratio reduction (RRR) of $15 \%$ average survival and loss at follow-up of $1 \%$ [32]. The $z$-curve was constructed based on consecutive $z$-values, calculated using two-sided significant testing. The monitoring boundaries were constructed using conventional testing and by applying the O'Brien-Fleming $\alpha$-spending function. The total number of observed patients in the cumulative meta-analysis was defined as the accrued information size (AIS). The TSA was performed using the Stata 14 software program [33].

\section{Results}

\section{Systematic review}

The selection process flow chart is reported in Fig. 1. Initial search identified 661 publications. After removing duplicates, 431 titles and abstracts were reviewed. Further screening found 15 RCTs meeting the inclusion criteria. The included RCTs had issues regarding blinding taking into consideration that the application of blinding into surgical RCTs is challenging. The method of randomization was reported in 9 studies, while 13 RCTs described the operating surgeon's proficiency. Details regarding the power analysis were specified in 4 studies (Supplementary Table 1). None of the studies received a low risk of bias on all assessed items. Because of the lack of patients and/or outcomes assessors blinding, all trials were graded as having high/unclear risk of performance and detection bias (Supplementary Figure 1).

Overall, 1359 patients were included in the analysis. Of these, 702 (51.6\%) underwent TAPP and 657 (48.4\%) TEP repair (Table 1). The sample size of the individual studies ranged from 40 to 314 . The age of the patients ranged from 18 to 92 years and $87.9 \%$ were males. The American Society of Anesthesiologists (ASA) score and patients' comorbidities were reported in six studies, while the BMI was reported in four trials. Overall, 86 (6.3\%) underwent bilateral hernia repair while 60 patients $(4.4 \%)$ were operated for recurrence. All trials reported the surgical technique, ten specified the type of hernia, and twelve reported the type of mesh and fixation techniques.

All studies reported intraoperative complications; inadvertent hollow viscus injury was not reported, while inadvertent bleeding from right inferior epigastric artery was reported in $0.4 \%$ of patients (TAPP $n=1$ and TEP $n=4$ ). Conversion to minimally invasive approach to open repair was reported in $0.45 \%$ of patients for technical reasons (TAPP $n=2$ and TEP $n=4$ ), while conversion from TEP to TAPP was reported in 3 patients because preperitoneal adhesions $(n=2)$ and inadvertent peritoneal tear $(n=1)$. Postoperative follow-up duration ranged from 1 to 44 months. There were no mortalities.

\section{Meta-analysis and TSA: primary outcomes}

Eleven studies (1040 patients) reported postoperative hernia recurrence with similar RR for TEP vs. TAPP $(\mathrm{RR}=0.83$; 95\% CI 0.35-1.96) (Fig. 2a). The prediction lower and upper limits are 0.28 and 2.43 , respectively. The heterogeneity is zero $\left(I^{2}=0.0 \%\right.$; 95\% CI $\left.0.0-0.0 ; p=0.99\right)$ and $\tau^{2}=0.0$. Visual inspection of the Funnel plot does not show evidence of publication bias (Fig. 2b). The sensitivity analysis shows the robustness of these findings in terms of point estimation, relative confidence intervals, and heterogeneity. The sub-analysis including studies with $>12$-month follow-up showed similar results (Table 2). The TSA, assuming an anticipated intervention effect of $15 \%$ RRR, shows a cumulative $z$-curve without crossing the monitoring boundaries curve (Fig. 2c). The required information size is reached and further trials are unlikely to demonstrate a statistically significant effect between the two techniques. This is a true negative result. 
Fig. 1 The Preferred Reporting Items for Systematic Reviews and meta-analysis checklist (PRISMA) diagram
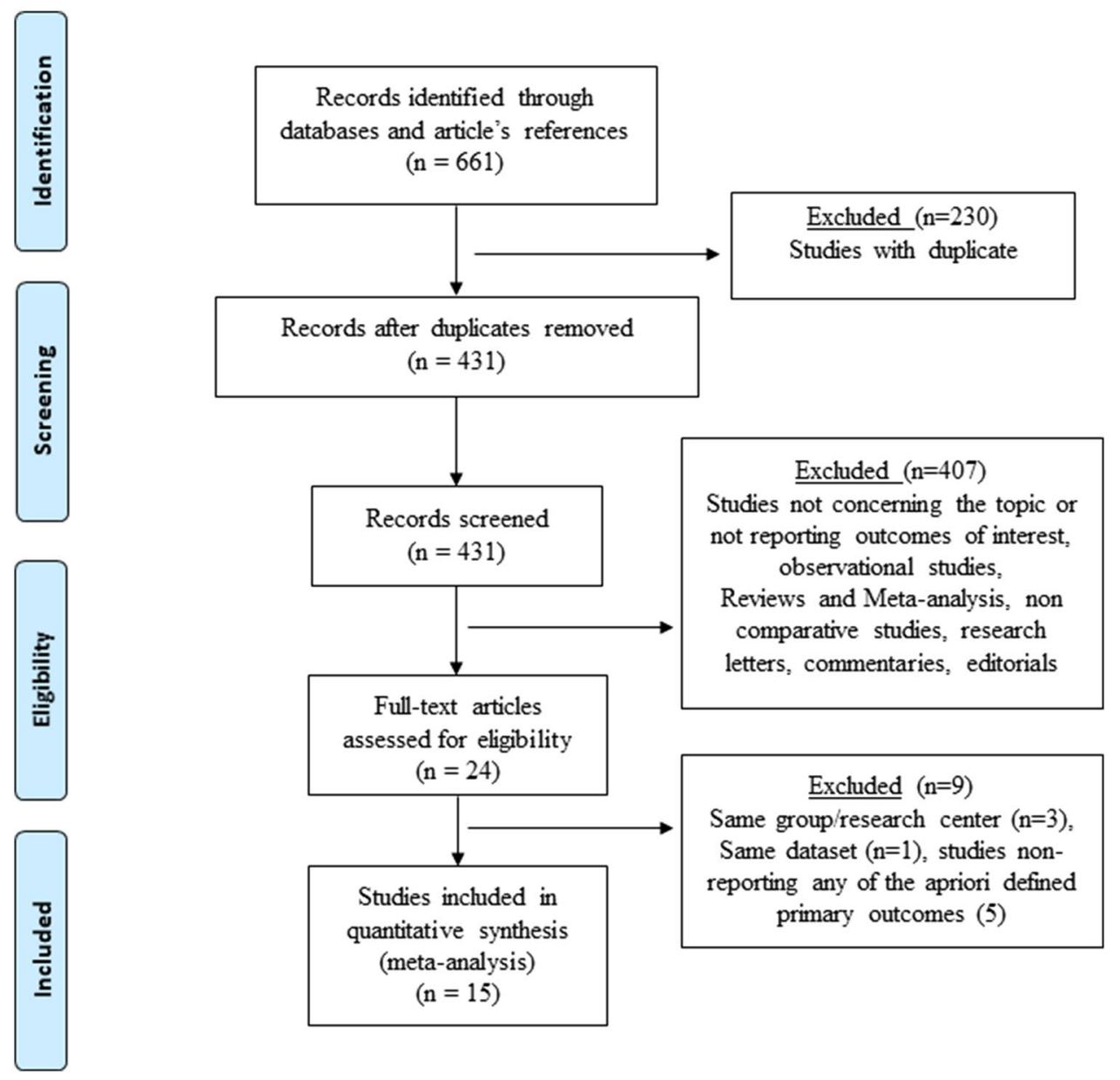

Seven studies (873 patients) reported postoperative chronic pain with similar RR for TEP vs. TAPP $(\mathrm{RR}=1.51$; 95\% CI 0.54-4.22) (Fig. 3a). The prediction lower and upper limits are 0.16 and 14.4 , respectively. The heterogeneity is zero $\left(I^{2}=0.0 \%\right.$; 95\% CI $\left.0.0-44.0 ; p=0.84\right)$ and $\tau^{2}=0.0$. The sensitivity analysis shows the robustness of these findings in terms of point estimation, relative confidence intervals, and heterogeneity. The sub-analysis including studies with > 12-month follow-up showed similar results (Table 2). The TSA, assuming an anticipated intervention effect of $15 \%$ RRR, shows a cumulative z-curve without crossing the monitoring boundaries curve (Fig. 3b). The required information size is reached and further trials are unlikely to demonstrate a statistically significant effect between the two techniques. This is a true negative result.

\section{Meta-analysis: secondary outcomes}

The postoperative VAS score at $<12-\mathrm{h}, 24 \mathrm{~h}, 48 \mathrm{~h}, 1$ week, 1 month, and 3 months was similar for TEP vs. TAPP repair. Similarly, the analysis for wound-related complications showed equivalent postoperative hematoma, seroma, and wound infection RR. Operative time
(WMD $=0.09 ; 95 \% \mathrm{CI}-0.41 ; 0.58)$ and hospital length of stay (WMD $=0.22 ; 95 \% \mathrm{CI}-0.22 ; 0.66)$ were similar between techniques. Eight studies (873 patients) reported return to work/daily activities with similar results for TEP vs. TAPP $(\mathrm{WMD}=-0.03 ; 95 \% \mathrm{CI}-0.26 ; 0.21)$. The League table for all outcomes is reported in Table 2.

\section{Discussion}

This meta-analysis shows that TEP and TAPP have comparable hernia recurrence and postoperative chronic pain. The trial sequential analysis shows that the information size is adequate, while future trials are unlikely to demonstrate a significant difference between the two techniques and should be avoided.

The recent European Hernia Society's guidelines stated that Lichtenstein tension-free and minimally invasive techniques such as TAPP and TEP, performed by expert surgeons, are suggested as the best evidence-based options for inguinal hernia repair [1]. Approximately, 20\% of patients with primary inguinal hernia underwent minimally invasive 
Table 1 Demographic and clinical characteristics of patients undergoing laparoscopic trans abdominal pre-peritoneal (TAPP) and totally extra peritoneal (TEP) repair

\begin{tabular}{|c|c|c|c|c|c|c|c|c|}
\hline Author & Country & $\begin{array}{l}\text { Surgical pro- } \\
\text { cedure }\end{array}$ & No. patients & Age (years) & $\begin{array}{l}\text { Gender } \\
\text { (male) }\end{array}$ & Type of hernia & Type of mesh & Follow-up (mos) \\
\hline $\begin{array}{l}\text { Schrenk et al. } \\
\text { [34] }\end{array}$ & Australia & TAPP/TEP & $28 / 24$ & $\begin{array}{l}39.1 \pm 14.3 \\
42.3 \pm 11.9\end{array}$ & $24 / 22$ & $\begin{array}{l}\text { Indirect: } \\
\text { 19/18, } \\
\text { Direct: 9/6 }\end{array}$ & $\begin{array}{l}\text { Polypropylene } \\
\text { mesh (TAPP: } \\
\text { SurgiPro®, } \\
\text { Auto Suture }{ }^{\circ} \text {; } \\
\text { TEP: Sur- } \\
\text { giPro®) }\end{array}$ & $\mathrm{nr}$ \\
\hline $\begin{array}{l}\text { Dedemadi } \\
\text { et al. [35] }\end{array}$ & Greece & TAPP/TEP & $24 / 26$ & $65(28-92)$ & $\mathrm{nr}$ & $\begin{array}{l}\text { Nyhus class } \\
\text { II } 14 / 16 \text {, } \\
\text { IIIA } 7 / 8 \text {, } \\
\text { IIIC } 3 / 2\end{array}$ & $\begin{array}{l}\text { TAPP: nr } \\
\text { TEP: non } \\
\text { absorbable } \\
\text { mesh }\end{array}$ & $30 \pm 1$ \\
\hline $\begin{array}{l}\text { Gunal et al. } \\
\text { [36] }\end{array}$ & Turkey & TAPP/TEP & $39 / 40$ & $\begin{array}{l}25.7 \pm 1 \\
22.3 \pm 0.6\end{array}$ & $\mathrm{nr}$ & $\begin{array}{l}\text { Nyhus class: I, } \\
\text { II, IIIA, IIIB }\end{array}$ & $\begin{array}{l}\text { Polypropilene } \\
\text { mesh } \\
(6 \times 12 \mathrm{~cm})\end{array}$ & $\mathrm{nr}$ \\
\hline $\begin{array}{l}\text { Butler et al. } \\
\text { [37] }\end{array}$ & USA & TAPP/TEP & $22 / 22$ & $\mathrm{nr}$ & $\mathrm{nr}$ & $\mathrm{nr}$ & $\begin{array}{l}\text { Polypropylene } \\
\text { mesh }\end{array}$ & 1 \\
\hline $\begin{array}{l}\text { Pokorny et al. } \\
\text { [38] }\end{array}$ & Austria & TEP/TAPP & $36 / 93$ & $\begin{array}{l}49(19-73) \\
49(21-78)\end{array}$ & $35 / 86$ & $\mathrm{nr}$ & $\begin{array}{l}\text { Polypropylene } \\
\text { mesh }\end{array}$ & 36 \\
\hline Zhu et al. [39] & China & TAPP/TEP & $20 / 20$ & $\begin{array}{l}62.3 \pm 12 \\
60.2 \pm 9.7\end{array}$ & $19 / 20$ & $\mathrm{nr}$ & $\mathrm{nr}$ & $\mathrm{nr}$ \\
\hline $\begin{array}{l}\text { Hamza et al. } \\
{[40]}\end{array}$ & Egypt & TAPP/TEP & $25 / 25$ & $\begin{array}{l}36.7 \pm 12 \\
34.9 \pm 13\end{array}$ & $25 / 25$ & $\begin{array}{l}\text { Nyhus class } \\
\text { I-III }\end{array}$ & $\mathrm{nr}$ & 24 \\
\hline $\begin{array}{l}\text { Krishna et al. } \\
\text { [41] }\end{array}$ & India & TEP/TAPP & $53 / 47$ & $\begin{array}{l}47.8 \pm 16 \\
51.3 \pm 13.8\end{array}$ & $52 / 47$ & $\begin{array}{l}\text { Indirect: } \\
\text { 37/41, } \\
\text { Direct: } 26 / 18\end{array}$ & $\begin{array}{l}\text { Heavyweight } \\
\text { polypro- } \\
\text { pilene mesh } \\
(10 \times 15 \mathrm{~cm}) \\
\text { preshaped } \\
\text { 3Dmax } \\
\text { polypropylene } \\
\text { mesh }\end{array}$ & 30 \\
\hline $\begin{array}{l}\text { Gong et al. } \\
\text { [42] }\end{array}$ & China & TAPP/TEP & $50 / 52$ & $\begin{array}{l}56 \pm 10 \\
57 \pm 9\end{array}$ & $50 / 52$ & $\begin{array}{l}\text { Indirect: } \\
\text { 35/37, } \\
\text { Direct: } 9 / 11 \text {, } \\
\text { Both: } 6 / 4\end{array}$ & $\begin{array}{l}\text { TAPP: polypro- } \\
\text { pylene mesh } \\
(8.5 \times 15 \mathrm{~cm}) \\
\text { TEP: Bard® } \\
\text { 3Dmax } \\
(8.5 \times 13 \mathrm{~cm})\end{array}$ & $16 \pm 8$ \\
\hline $\begin{array}{l}\text { Mesci et al. } \\
\text { [43] }\end{array}$ & Turkey & TAPP/TEP & $25 / 25$ & $\begin{array}{l}48.2 \\
48.4\end{array}$ & $\mathrm{nr}$ & $\begin{array}{l}\text { Indirect: } 12 / 12 \\
\text { Direct: } 8 / 7 \\
\text { Both: } 5 / 7\end{array}$ & $\mathrm{nr}$ & $\mathrm{nr}$ \\
\hline $\begin{array}{l}\text { Wang et al. } \\
\text { [44] }\end{array}$ & China & TAPP/TEP & $84 / 84$ & $\begin{array}{l}48.2 \pm 13.2 \\
52.1 \pm 17.4\end{array}$ & $70 / 71$ & $\begin{array}{l}\text { Indirect: } \\
\text { 77/73, } \\
\text { Direct: } 6 / 8 \text {, } \\
\text { Femoral: } 1 / 3\end{array}$ & $\begin{array}{l}\text { TAPP: vypro } \\
\text { II mesh } \\
(12 \times 15 \mathrm{~cm}) \\
\text { TEP: vypro II } \\
\text { mesh } \\
(10 \times 15 \mathrm{~cm})\end{array}$ & $16 \pm 7$ \\
\hline
\end{tabular}


Table 1 (continued)

\begin{tabular}{|c|c|c|c|c|c|c|c|c|}
\hline Author & Country & $\begin{array}{l}\text { Surgical pro- } \\
\text { cedure }\end{array}$ & No. patients & Age (years) & $\begin{array}{l}\text { Gender } \\
\text { (male) }\end{array}$ & Type of hernia & Type of mesh & Follow-up (mos) \\
\hline $\begin{array}{c}\text { Bansal et al. } \\
\text { [45] }\end{array}$ & India & TEP/TAPP & $160 / 154$ & $\begin{array}{l}50.7 \pm 17.3 \\
43.4 \pm 16.4\end{array}$ & $\mathrm{nr}$ & $\mathrm{nr}$ & $\begin{array}{l}\text { Preshaped } \\
\text { 3Dmax } \\
\text { polypropylene } \\
\text { mesh large } \\
\text { size }(\text { Bard } ® \text {, } \\
10.8 \times 16 \mathrm{~cm}) \text {; } \\
\text { Flat heavy- } \\
\text { weight } \\
\text { polypropylene } \\
\text { mesh }(\text { size } \\
15 \times 10 \mathrm{~cm}) ; \\
\text { Lightweight } \\
\text { polypropyl- } \\
\text { ene mesh } \\
\text { (Prolene soft, } \\
\text { Ethicon®, } \\
15 \times 10 \mathrm{~cm})\end{array}$ & $30 \pm 14$ \\
\hline $\begin{array}{l}\text { Jeelani et al. } \\
\text { [46] }\end{array}$ & India & TAPP/TEP & $30 / 30$ & $\begin{array}{l}48.2 \pm 13.3 \\
46.7 \pm 13\end{array}$ & $29 / 30$ & $\mathrm{nr}$ & $\begin{array}{l}\text { Polypropilene } \\
\text { mesh } \\
(10 \times 15 \mathrm{~cm})\end{array}$ & 24 \\
\hline $\begin{array}{l}\text { Ciftci et al. } \\
\text { [47] }\end{array}$ & Turkey & TEP/TAPP & $30 / 31$ & $\begin{array}{l}44.4 \pm 15.3 \\
45.7 \pm 11.1\end{array}$ & $26 / 26$ & $\begin{array}{l}\text { Indirect: } 20 / 20 \text {, } \\
\text { Direct: } 3 / 4, \\
\text { Both } 7 / 7\end{array}$ & $\begin{array}{l}\text { Polypropilene } \\
\text { mesh } \\
(15 \times 8 \mathrm{~cm})\end{array}$ & 3 \\
\hline $\begin{array}{l}\text { Sharma et al. } \\
\text { [48] }\end{array}$ & India & TAPP/TEP & $30 / 30$ & $\begin{array}{l}49.4 \\
49\end{array}$ & 59 & $\begin{array}{r}\text { Indirect: 33/28, } \\
\text { Direct: } 27 / 32\end{array}$ & $\begin{array}{l}\text { Polypropilene } \\
\text { mesh } \\
(10 \times 12 \mathrm{~cm})\end{array}$ & 1 \\
\hline
\end{tabular}

Data are reported as numbers, mean \pm standard deviation, median (range)

mos months, $n r$ not reported

approach $[49,50]$. Reasons of such a low percentage are probably related to higher direct costs and steep learning curve. However, a recent network analysis of RCT showed that both TEP and TAPP seem associated with reduced risk of postoperative pain and shorter return to work/daily activities compared to open tension-free repair [11].

Hernia recurrence after minimally invasive repair has been reported up to $2 \%$ for both TEP and TAPP repair [1-3]. Mesh type, size, and overlap, technique for mesh fixation (Self-gripping vs. sutured meshes vs. tacker vs. glue fixation), medial or lateral hernia sac, sliding hernia, operating time, type of anesthesia, participation in a register database, femoral hernia, adequate dissection and space creation, postoperative complications, and center/surgeon volume have been identified as risk factors [51-54]. The present analysis shows comparable results in terms of postoperative hernia recurrence RR. The global heterogeneity was zero $\left(I^{2}=0.0 \%\right)$ indicating a low degree of variability across studies, thus giving consistence to the result. This is similar to previously published studies and meta-analyses reporting similar postoperative hernia recurrence for TEP and TAPP repair [15-21]. Interestingly, no differences were found in the subgroup analysis including studies with $>12$-month follow-up. Postoperative chronic pain after minimally invasive repair has been reported up to $3 \%$ [11]. The present quantitative analysis showed comparable RR for TEP vs. TAPP $(\mathrm{RR}=1.51 ; 95 \% \mathrm{CI} 0.54-4.22)\left(I^{2}=0.0 \%\right)$ and no significant differences were found when considering studies with more than 12-month follow-up. This is in line with previously published studies that reported similar odds for chronic pain comparing TAPP and TEP repair [15-21]. So far, there is no conclusive evidence of differences in proportions for postoperative hernia recurrence and chronic pain for the TEP vs. TAPP comparison. Interestingly, the performed TSA suggested that the required sample was reached and the lack of statistical significance is a true negative results. Therefore, further trials or meta-analyses seem unlikely to demonstrate diverse results in term of postoperative hernia recurrence and chronic pain and should be avoided. These are key finding for the surgical community while research efforts should be focused on specific subgroups analysis (i.e., gender specifics, unilateral, bilateral, recurrence, high-risk patients, etc.), development of tailored strategies, patient-reported outcomes, and long-term follow-up ( $>5$ years).

A precise indication about the period of convalescence after inguinal hernia repair is lacking. Existing evidence suggest that patients should be encouraged to resume their activities as soon as they feel comfortable and return to 
A

Study

Schrenk et al., 1996

Dedemadi et al., 2006

Gunal et al., 2007

Butler et al., 2007

Pokorny et al., 2008

Hamza et al., 2009

Krishna et al4., 2011

Gong et al., 2011

Bansal et al., 2013

Sharma et al., 2015

Jeelani et al., 2015

Fixed effect model

Random effects model

Prediction interval

Heterogeneity: $I^{2}=0 \%[<0 \% ;<0 \%], \tau^{2}=0, p=0.99$

Test for overall effect (foxed effect): $z=-0.42(p=0.67)$

Test for overall effect (random effects): $z=-0.42(p=0.67)$

B

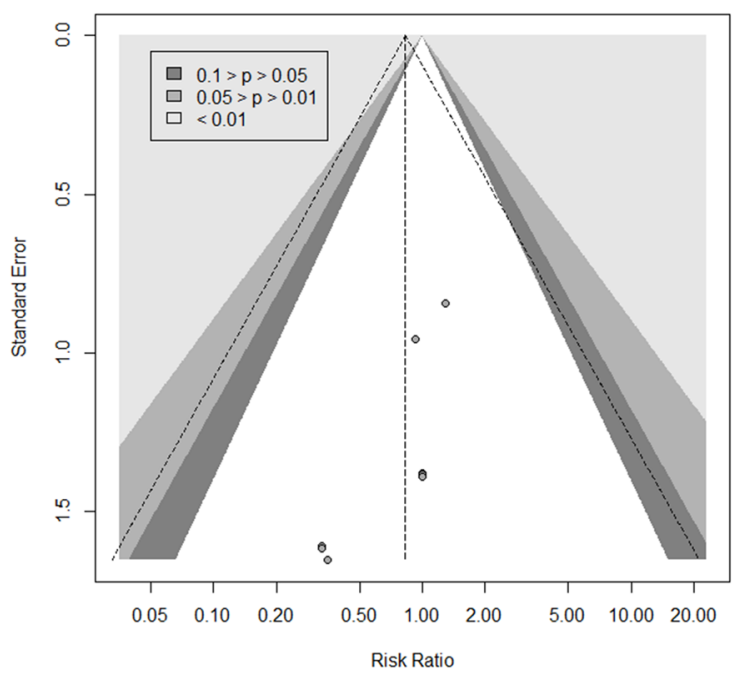

\section{Experimental Control} Events Total Events Total

Risk Ratio

$\begin{array}{rrrr}0 & 24 & 1 & 28 \\ 2 & 26 & 2 & 24 \\ 0 & 40 & 1 & 39 \\ 1 & 22 & 1 & 22 \\ 2 & 36 & 4 & 93 \\ 1 & 25 & 1 & 25 \\ 0 & 53 & 0 & 47 \\ 0 & 52 & 0 & 50 \\ 0 & 160 & 1 & 154 \\ 0 & 30 & 0 & 30 \\ 1 & 30 & 1 & 30\end{array}$

498

542

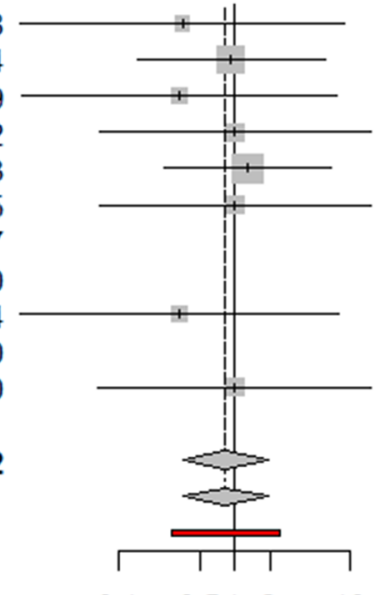

$\begin{array}{llll}0.1 & 0.51 & 2 & 10\end{array}$
RR $\quad 95 \%-\mathrm{Cl}$ Weight $\begin{gathered}\text { Weight } \\ \text { (fixed) (random) }\end{gathered}$

$0.35[0.01 ; 8.98] \quad 7.0 \% \quad 7.0 \%$

$0.92[0.14 ; 6.05] \quad 21.0 \% \quad 21.0 \%$

$0.33 \quad[0.01 ; 7.77] \quad 7.4 \% \quad 7.4 \%$

$1.00[0.07 ; 15.00] \quad 10.1 \% \quad 10.1 \%$

$1.29[0.25 ; 6.75] \quad 27.1 \% \quad 27.1 \%$

$1.00[0.07 ; 15.12] \quad 10.0 \% \quad 10.0 \%$

$0.0 \% \quad 0.0 \%$

$0.0 \% \quad 0.0 \%$

$0.33[0.01 ; 7.86] \quad 7.4 \% \quad 7.4 \%$

$0.0 \% \quad 0.0 \%$

$1.00[0.07 ; 15.26] \quad 10.0 \% \quad 10.0 \%$

$0.83[0.35 ; 1.96] 100.0 \%$

$0.83[0.35 ; 1.96] \quad--100.0 \%$

C

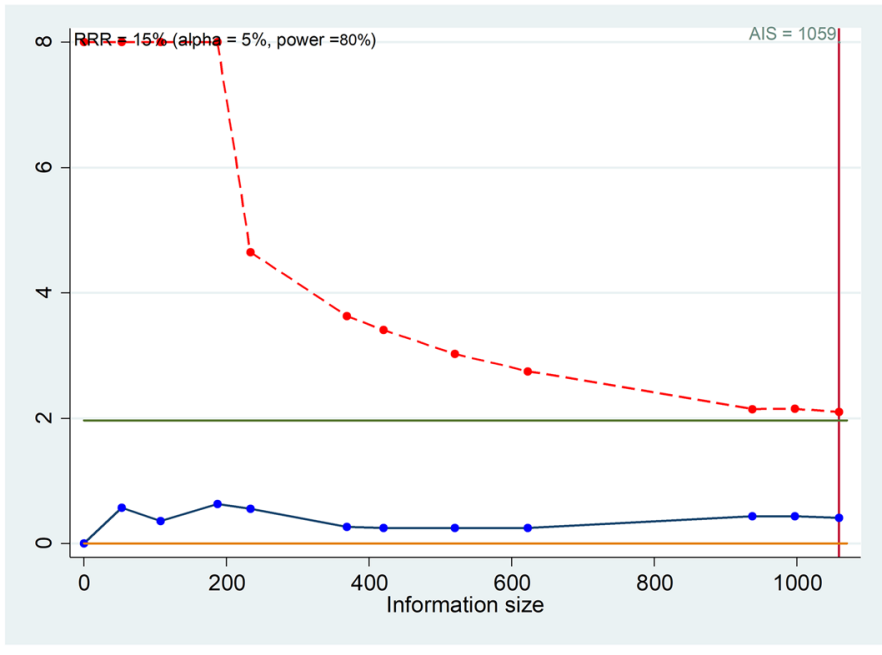

Fig. 2 a-c Forrest plot (a), funnel plot (b) and trial sequential analysis (c) for postoperative hernia recurrence

work should be recommended if there is no excessive physical exertion and pain is controlled [52]. Significant variations exist because different confounders such as type of anesthesia, postoperative pain control, wound complications, preoperative patient expectations, motivation, culture, and administrative/insurance aspects may influence this aspect $[55,56]$. In accordance with previously published studies, our results seem to further corroborate that both TEP and TAPP repair are associated with comparable return to work/daily activities. Early postoperative pain was comparable among treatments. This is in contrast with Chen et al. and Bansal et al. who reported a trend toward reduced postoperative analgesia requirement and reduced postoperative pain for TEP repair up to 1-3 months [21, 45]. The authors affirmed that the peritoneal incision and closure with continuous suture may be responsible for high pain scores for TAPP repair. However, not only the peritoneal incision is determinant of postoperative pain, but also several factors including patients' subjective pain perception and expression, different protocols for anesthesia, postoperative analgesia, methods for mesh fixation (tacks vs. glue vs. self-gripping), mesh type, and weight $\left(\mathrm{g} / \mathrm{m}^{2}\right)$ have been shown to be additional causes of postoperative pain [56-59]. While our results seem to support equivalent 
Table 2 League table

\begin{tabular}{|c|c|c|c|c|}
\hline Categorical outcomes & $\mathrm{RR}(95 \% \mathrm{CI})$ & $I^{2}(95 \% \mathrm{CI})$ & No. studies & No. patients \\
\hline Hernia recurrence & $0.83(0.35-1.96)$ & $0.0 \%(0.0-0.0 \%)$ & 11 & 1040 \\
\hline Hernia recurrence (> 12-month follow-up) & $0.95(0.65-2.34)$ & $0.0 \%(0.0-0.0 \%)$ & 7 & 805 \\
\hline Chronic pain & $1.51(0.54-4.22)$ & $0.0 \%(0.0-44 \%)$ & 7 & 873 \\
\hline Chronic pain ( $>$ 12-month follow-up) & $1.42(0.63-3.84)$ & $0.0 \%(0.0-26 \%)$ & 6 & 821 \\
\hline Haematoma & $1.19(0.47-2.97)$ & $0.0 \%(0.0-53 \%)$ & 10 & 714 \\
\hline Seroma & $1.24(0.75-2.07)$ & $0.0 \%(0.0-32 \%)$ & 8 & 932 \\
\hline Wound infection & $0.45(0.17-1.17)$ & $0.0 \%(0.0-0.0 \%)$ & 9 & 916 \\
\hline Continuous outcomes & WMD $(95 \%$ CI $)$ & $I^{2}(95 \% \mathrm{CI})$ & No. studies & No. patients \\
\hline $\mathrm{VAS}<12 \mathrm{~h}$ & $-0.42(-0.82 ; 0.12)$ & $89 \%(81-93 \%)$ & 9 & 923 \\
\hline VAS $24 \mathrm{~h}$ & $-0.35(-0.91 ; 0.22)$ & $93 \%(89-96 \%)$ & 9 & 891 \\
\hline VAS $48 \mathrm{~h}$ & $-0.06(-0.39 ; 0.27)$ & $48 \%(0.0-81 \%)$ & 5 & 285 \\
\hline VAS 1 week & $-0.41(-0.87 ; 0.18)$ & $81 \%(56-92 \%)$ & 4 & 508 \\
\hline VAS 1 month & $-0.29(-0.44 ; 0.14)$ & $56 \%(35-77 \%)$ & 4 & 516 \\
\hline VAS 3 months & $-0.38(-0.99 ; 0.22)$ & $91 \%(77-97 \%)$ & 2 & 414 \\
\hline Hospital length of stay (days) & $0.22(-0.22 ; 0.66)$ & $91 \%(85-94 \%)$ & 11 & 1018 \\
\hline Operative time (minutes) & $0.09(-0.41 ; 0.58)$ & $95 \%(93-96 \%)$ & 12 & 1188 \\
\hline Return to work (days) & $-0.03(-0.26 ; 0.21)$ & $49 \%(0.0-77 \%)$ & 8 & 691 \\
\hline Costs (US \$) & $0.46(-0.37 ; 1.29)$ & $96 \%(93-98 \%)$ & 4 & 684 \\
\hline
\end{tabular}

Each row represents a specific outcome. Values in each column represent the relative effect for the comparison TEP vs, TAPP. Values are expressed as Risk Ratio (RR), weighted mean difference (WMD), and 95\% confidence intervals (95\% CI)

$I^{2}$ Heterogeneity, VAS Visual Analog Scale

postoperative pain, the related heterogeneity is moderate and caution is mandatory.

Surgeon experience, expertise, variation in technical skills, and hospital volume are key determinants for operative time while TAPP and TEP have been shown to be associated with a steep learning curve $[60,61]$. The European Hernia Society stated that one hundred TAPP procedures are necessary to achieve comparable results with open mesh repair and that at least 50 cases are required to halve complication rates $[1,62]$. Lau et al. affirmed that at least 80 TEP repair are required to complete the learning curve, while Aeberhard et al. reported a significant drop in surgery duration after one hundred procedures $[63,64]$. In the present review, only three studies specified the operating surgeon proficiency $[38,44,48]$, while the others reported that surgeries were performed by experienced surgeons. The appreciation of different anatomical landmarks in combination with the presence of tissue adherences or bleeding may increase the difficulties in the creation and maintenance of a proper preperitoneal working space in TEP repair, particularly in the early phase of the learning curve [12]. The accidental injury of the peritoneal layer, bleeding, and adhesions have been reported as possible causes of conversion to TAPP or open repair [48]. In the present study, conversion from TEP to open approach was reported in four patients because technical reasons, while three patients were converted to TAPP because of adhesions and inadvertent peritoneal tear.
Some authors argued that TEP should be considered superior to TAPP repair because of the reduced risk of visceral injury. While this hypothesis is conceivable, in the present systematic review, none of the patients experienced inadvertent bowel or bladder injuries during TAPP. Notably, inadvertent injury of the inferior epigastric artery seems more frequent, while careful dissection should be performed to minimize this complication.

There are several limitations to the current analysis. First, although transitivity assumption was met with no evidence of statistically significant inconsistency, the accuracy of our results can be tempered by preoperative patients (men vs. women) and hernia characteristics (i.e., primary, recurrent, bilateral, etc.). Second, even though only RCTs were included in this review, the quality of evidence remained moderate, in part, due to the lack of patients, surgeons, and assessors blinding, limited power of some trials, different method for randomization and inclusion/exclusion criteria. Third, confounders related to surgeons' experience and expertise, inclusion and exclusion criteria, learning curve, hospital volumes, operative technique, mesh type, fixation techniques, outcomes reporting, and follow-up may be additional confounders.

In conclusion, this systematic review and trial sequential analysis shows that TEP and TAPP repair seems comparable in terms of hernia recurrence and chronic pain. The cumulative evidence and information size are 
A

Experimental Control Events Total Events Total

Schrenk et al., 1996

Dedemadi et al., 2006

Pokorny et al., 2008

Krishna et al., 2011

Wang et al., 2013

Bansal et al., 2013

Jeelani et al., 2015

Fixed effect model

Random effects model

$\begin{array}{rrrr}1 & 24 & 1 & 28 \\ 1 & 26 & 1 & 24 \\ 3 & 36 & 3 & 93 \\ 0 & 53 & 0 & 47 \\ 0 & 84 & 0 & 84 \\ 2 & 160 & 2 & 154 \\ 0 & 30 & 0 & 30\end{array}$

413

460

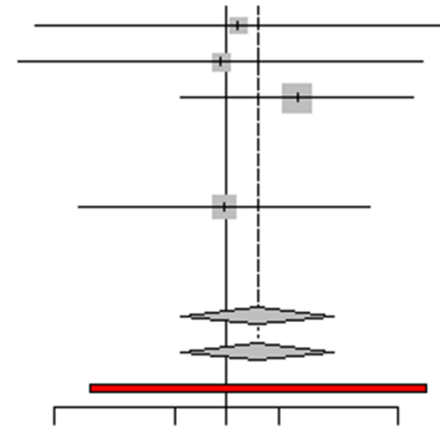

RR

Weight Weight

(fixed) (random)

\section{Prediction interval}

Heterogeneity: $I^{2}=0 \%[0 \% ; 44 \%], \tau^{2}=0, p=0.84$

Test for overall effect (foxed effect): $z=0.79(p=0.43$ )

Test for overall effect (random effects): $z=0.79(p=0.43)$

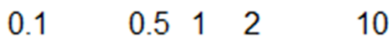

$1.17 \quad[0.08 ; 17.67] \quad 14.3 \% \quad 14.3 \%$

$0.92[0.06 ; 13.95] \quad 14.3 \% \quad 14.3 \%$

$2.58[0.55 ; 12.21] \quad 43.7 \% \quad 43.7 \%$

$0.0 \% \quad 0.0 \%$

$0.0 \% \quad 0.0 \%$

$0.96 \quad[0.14 ; 6.75] \quad 27.8 \% \quad 27.8 \%$

$0.0 \% \quad 0.0 \%$

$1.51[0.54 ; 4.22] 100.0 \%$

$1.51[0.54 ; 4.22]$

$[0.16 ; 14.41]$

- $100.0 \%$

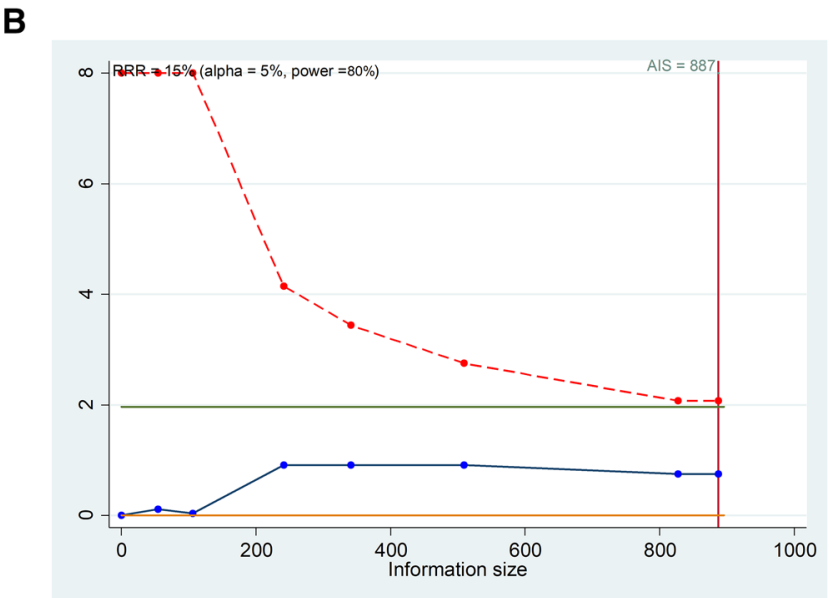

Fig. 3 a-b Forrest plot (a) and trial sequential analysis (b) for postoperative chronic pain

adequate to provide a conclusive evidence for both these outcomes. Similar trials or meta-analysis seem unlikely to show different results and should be discouraged.

Supplementary Information The online version contains supplementary material available at https://doi.org/10.1007/s10029-021-02407-7.

Author contributions AA, MC, SDF and LM did the literature search. $\mathrm{AA}, \mathrm{GC}$ and DB formed the study design. Data collection done by AA, FL, VP and PGB. AA, GB and DB analyzed the data. AA, GC and DB interpreted the data. AA, GB and DB wrote the manuscript. AA, GC and DB critically reviewed the manuscript.

Funding Open access funding provided by Università degli Studi di Milano within the CRUI-CARE Agreement. None.

\section{Declarations}

Conflict of interest AA, MC, SDF, LM, FL, GB, PGB, VP, GC, and DB declare no conflicts of interest.
Ethical approval Approval from the Institutional review board was not required for this study.

Human and animal rights This article does not contain any studies with human participants or animals performed by any of the authors.

Informed consent For this systematic review and meta-analysis, formal consent is not required.

Open Access This article is licensed under a Creative Commons Attribution 4.0 International License, which permits use, sharing, adaptation, distribution and reproduction in any medium or format, as long as you give appropriate credit to the original author(s) and the source, provide a link to the Creative Commons licence, and indicate if changes were made. The images or other third party material in this article are included in the article's Creative Commons licence, unless indicated otherwise in a credit line to the material. If material is not included in the article's Creative Commons licence and your intended use is not permitted by statutory regulation or exceeds the permitted use, you will need to obtain permission directly from the copyright holder. To view a copy of this licence, visit http://creativecommons.org/licenses/by/4.0/. 


\section{References}

1. The HerniaSurge Group (2018) International guidelines for groin hernia management. Hernia 22(1):1-165

2. Kingsnorth A, LeBlanc K (2003) Hernias: inguinal and incisional. Lancet 362(9395):1561-1571

3. Aiolfi A, Cavalli M, Micheletto G et al (2019) Primary inguinal hernia: systematic review and Bayesian network meta-analysis comparing open, laparoscopic transabdominal preperitoneal, totally extraperitoneal, and robotic preperitoneal repair. Hernia 23(3):473-484

4. Arregui ME, Davis CJ, Ucel O et al (1992) Laparoscopic mesh repair of inguinal hernia using a pre-peritoneal approach: a preliminary report. Surg Laparosc Endosc 2:53-58

5. Dion YM, Morin J (1992) Laparoscopic inguinal herniorrhaphy. Can J Surg 35(2):209-212

6. Ferzli GS, Massad A, Albert P (1992) Extraperitoneal endoscopic inguinal hernia repair. J Laparoendosc Surg 2(6):281-286

7. McKernan B (1992) Laparoscopic pre-peritoneal prosthetic repair of inguinal hernias. Surg Rounds 7:579-610

8. Bittner R, Arregui ME, Bisgaard T et al (2011) Guidelines for laparoscopic (TAPP) and endoscopic (TEP) treatment of inguinal Hernia [International Endohernia Society (IEHS)]. Surg Endosc 25:2773-2843

9. Aiolfi A, Cavalli M, Micheletto G, Bruni PG, Lombardo F, Perali C, Bonitta G, Bona D (2019) Robotic inguinal hernia repair: is technology taking over? Systematic review and meta-analysis. Hernia 23(3):509-519. https://doi.org/10.1007/ s10029-019-01965-1

10. Bittner R, Montgomery MA, Arregui E et al (2015) Update of guidelines on laparoscopic (TAPP) and endoscopic (TEP) treatment of inguinal hernia (International Endohernia Society). Surg Endosc 29(2):289-321

11. Aiolfi A, Cavalli M, Del Ferraro S et al (2021) Treatment of inguinal hernia: systematic review and updated network metaanalysis of randomized controlled trials. Ann Surg. https://doi. org/10.1097/SLA.0000000000004735 (Epub ahead of print)

12. Köckerling F (2019) TEP for elective primary unilateral inguinal hernia repair in men: what do we know? Hernia 23(3):439-459

13. Bittner R, Schwarz J (2012) Inguinal hernia repair: current surgical techniques. Langenbecks Arch Surg 397(2):271-282

14. Bittner R, Schwarz J (2019) Primary unilateral not complicated inguinal hernia: our choice of TAPP, why, results and review of literature. Hernia 23:417-428

15. Köckerling F, Bittner R, Kofler M, Mayer F, Adolf D, Kuthe A, Weyhe D (2017) Lichtenstein versus total extraperitoneal patch plasty versus transabdominal patch plasty technique for primary unilateral inguinal hernia repair. Ann Surg 15:15-85

16. McCormack K, Wake BL, Fraser C, Vale L, Perez J, Grant A (2005) Transabdominal pre-peritoneal (TAPP) versus totally extraperitoneal (TEP) laparoscopic techniques for inguinal hernia repair: a systematic review. Hernia 9:109-114

17. Wake BL, McCormack K, Fraser C, Vale L, Perez J, Grant A (2005) Transabdominal pre-peritoneal (TAPP) versus totally extraperitoneal (TEP) laparoscopic techniques for inguinal hernia repair: (review). Cochrane Database Syst Rev. https:// doi.org/10.1002/14651858.cd004703.pub2

18. Bracale U, Melillo P, Pignata G, Di Salvo E, Rovani M, Merola G, Pecchia L (2012) Which is the best laparoscopic approach for inguinal hernia repair: TEP or TAPP? A systematic review of the literature with a network meta-analysis. Surg Endosc 26:3355-3366

19. Antoniou SA, Antoniou GA, Bartsch DK, Fendrich V, Koch OO, Pointner R, Granderath FA (2013) Transabdominal preperitoneal versus totally extraperitoneal repair of inguinal hernia: a metaanalysis of randomized studies. Am J Surg 206:245-252

20. Wei FX, Zhang YC, Wei H, Zhang YL, Shao Y, Ni R (2015) Transabdominal pre-peritoneal (TAPP) versus totally extraperitoneal (TEP) for laparoscopic hernia repair: a meta-analysis. Surg Laparosc Endosc Percutan Tech 25:375-383

21. Chen LS, Chen WC, Kang YN, Wu CC, Tsai LW, Liu MZ (2019) Effects of transabdominal preperitoneal and totally extraperitoneal inguinal hernia repair: an update systematic review and meta-analysis of randomized controlled trials. Surg Endosc $33: 418-428$

22. Liberati A, Altman DG, Tetzlaff J et al (2009) The PRISMA statement for reporting systematic reviews and meta-analyses of studies that evaluate healthcare interventions: explanation and elaboration. BMJ 339:b2700. https://doi.org/10.1136/bmj.b2700

23. Goossen K, Tenckhoff S, Probst P et al (2018) Optimal literature search for systematic reviews in surgery. Langenbecks Arch Surg 403(1):119-129

24. Higgins JP, Altman DG, Gotzsche PC, Cochrane Bias Methods Group; Cochrane Statistical Methods Group et al (2011) The Cochrane Collaboration's tool for assessing risk of bias in randomised trials. BMJ 343:d5928

25. DerSimonian R, Laird N (1986) Meta-analysis in clinical trials. Control Clin Trials 7(3):177-188

26. Borenstein M, Hedges LV, Higgins JP, Rothstein HR (2010) A basic introduction to fixed-effect and random-effects models for meta-analysis. Res Synth Methods 1(2):97-111

27. Higgins JP, Thompson SG, Deeks JJ, Altman DG (2003) Measuring inconsistency in meta-analyses. BMJ 327:557-560

28. Aiolfi A, Asti E, Bonitta G, Bonavina L (2018) Esophagectomy for end-stage Achalasia: systematic review and meta-analysis. World J Surg 42(5):1469-1476

29. Higgins JP, Thompson SG (2002) Quantifying heterogeneity in a meta-analysis. Stat Med 21(11):1539-1558

30. R Development Core Team (2015) A language and enviroment for statistical computing. R Foundation for Statistical Computing, Vienna. ISBN 3-900051-07-0

31. Miladinovic B, Mhaskar R, Hozo I, Kumar A, Mahony H, Djulbegovic B (2013) Optimal information size in trial sequential analysis of time-to-event outcomes reveals potentially inconclusive results because of the risk of random error. J Clin Epidemiol 66(6):6

32. O'Brien PC, Fleming TR (1979) A multiple testing procedure for clinical trials. Biometrics 35(3):549-556

33. StataCorp. (2015) Stata Statistical Software: Release 14. StataCorp LP, College Station

34. Schrenk P, Woisetschläger R, Rieger R et al (1996) Prospective randomized trial comparing postoperative pain and return to physical activity after transabdominal preperitoneal, total preperitoneal or Shouldice technique for inguinal hernia repair. Br J Surg 83(11):1563-1566

35. Dedemadi G, Sgourakis G, Karaliotas C et al (2006) Comparison of laparoscopic and open tension-free repair of recurrent inguinal hernias: a prospective randomized study. Surg Endosc 20(7):1099-1104

36. Günal O, Ozer S, Gürleyik E et al (2007) Does the approach to the groin make a difference in hernia repair? Hernia 11(5):429-434

37. Butler RE, Burke R, Schneider JJ et al (2007) The economic impact of laparoscopic inguinal hernia repair: results of a double-blinded, prospective, randomized trial. Surg Endosc 21(3):387-390

38. Pokorny H, Klingler A, Schmid T et al (2008) Recurrence and complications after laparoscopic versus open inguinal hernia repair: results of a prospective randomized multicenter trial. Hernia 12(4):385-389 
39. Zhu Q, Mao Z, Yu B et al (2009) Effects of persistent CO(2) insufflation during different laparoscopic inguinal hernioplasty: a prospective, randomized, controlled study. J Laparoendosc Adv Surg Tech A 19(5):611-614

40. Hamza Y, Gabr E, Hammadi H et al (2010) Four-arm randomized trial comparing laparoscopic and open hernia repairs. Int J Surg $8(1): 25-28$

41. Krishna A, Misra MC, Bansal VK et al (2012) Laparoscopic inguinal hernia repair: transabdominal preperitoneal (TAPP) versus totally extraperitoneal (TEP) approach: a prospective randomized controlled trial. Surg Endosc 26(3):639-649

42. Gong K, Zhang N, Lu Y et al (2011) Comparison of the open tension-free mesh-plug, transabdominal preperitoneal (TAPP), and totally extraperitoneal (TEP) laparoscopic techniques for primary unilateral inguinal hernia repair: a prospective randomized controlled trial. Surg Endosc 25(1):234-239

43. Mesci A, Korkmaz B, Dinckan A, Colak T, Balci N, Ogunc G (2012) Digital evaluation of the muscle functions of the lower extremities among inguinal hernia patients treated using three different surgical techniques: a prospective randomized study. Surg Today 42(2):157-163

44. Wang WJ, Chen JZ, Fang Q et al (2013) Comparison of the effects of laparoscopic hernia repair and Lichtenstein tension-free hernia repair. J Laparoendosc Adv Surg Tech A 23(4):301-305

45. Bansal VK, Misra MC, Babu D et al (2013) A prospective, randomized comparison of long-term outcomes: chronic groin pain and quality of life following totally extraperitoneal (TEP) and transabdominal preperitoneal (TAPP) laparoscopic inguinal hernia repair. Surg Endosc 27(7):2373-2382

46. Jeelani S, Ahmad MS, Dar et al (2015) A comparative study of transabdominal preperitoneal (TAPP) verses totally extra-peritoneal (TEP) Mesh repair of inguinal hernia. Appl Med Res. https:// doi.org/10.5455/amr.20150403124300

47. Ciftci F, Abdulrahman I, Ibrahimoglu F, Kilic G (2015) Earlystage quantitative analysis of the effect of laparoscopic versus conventional inguinal hernia repair on physical activity. Chirurgia (Bucur) 110(5):451-456

48. Sharma D, Yadav K, Hazrah P, Borgharia S, Lal R, Thomas S (2015) Prospective randomized trial comparing laparoscopic transabdominal preperitoneal (TAPP) and laparoscopic totally extra peritoneal (TEP) approach for bilateral inguinal hernias. Int J Surg 22:110-117

49. Maneck M, Köckerling F, Fahlenbrach C et al (2020) Hospital volume and outcome in inguinal hernia repair: analysis of routine data of 133,449 patients. Hernia 24:747-757

50. Estridge P, Sanders DL, Kingsnorth AN (2019) Worldwide hernia repair: variations in the treatment of primary unilateral inguinal hernias in adults in the United Kingdom and in low- and middleincome countries. Hernia 23:503-507

51. Niebuhr H, Köckerling F (2017) Surgical risk factors for recurrence in inguinal hernia repair-a review of the literature. Innov Surg Sci 2(2):53-59
52. Simons MP, Aufenacker TJ, Berrevoet F et al (2017) World Guidelines for Groin Hernia Management. www.herniasurge.com

53. Miserez M, Peeters E, Aufenacker T et al (2014) Update with level 1 studies of the European Hernia Society guidelines on the treatment of inguinal hernia in adult patients. Hernia 18:151-163

54. Campanelli G (2020) Basic research, experimental surgery and clinical research: where there is science, there is better treatment. Hernia 24:681-682

55. Forbes J, Fry N, Hwang H et al (2012) Timing of return to work after hernia repair: recommendations based on a literature review. BCMJ 54(7):341-345

56. Grewal P (2014) Survey of post-operative instructions after inguinal hernia repair in England in 2012. Hernia 18(2):269-272. https://doi.org/10.1007/s10029-013-1075-x (Epub 2013 Mar 31)

57. Bruni PG, Cavalli M, Aiolfi A et al (2019) Primary unilateral not complicated inguinal hernia with an effective, cheap, less invasive, and easy operation: the Trabucco repair. Hernia 23(3):555-560

58. Melkemichel M, Bringman S, Nilsson H et al (2020) Patientreported chronic pain after open inguinal hernia repair with lightweight or heavyweight mesh: a prospective, patient-reported outcomes study. Br J Surg. https://doi.org/10.1002/bjs.11755 (Online ahead of print)

59. Bakker WJ, Aufenacker TJ, Boschman JS et al (2020) Heavyweight mesh is superior to lightweight mesh in laparo-endoscopic inguinal hernia repair: a meta-analysis and trial sequential analysis of randomized controlled trials. Ann Surg. https://doi.org/10. 1097/SLA.0000000000003831 (Online ahead of print)

60. Stulberg JJ, Huang R, Kreutzer L et al (2020) Association between surgeon technical skills and patient outcomes. JAMA Surg 155(10):960-968

61. Köckerling F, Sheen AJ, Berrevoet F et al (2019) The reality of general surgery training and increased complexity of abdominal wall hernia surgery. Hernia 23(6):1081-1091

62. Neumayer L, Giobbie-Hurder A, Jonasson O et al (2004) Veterans Affairs Cooperative Studies Program 456 Investigators. Open mesh versus laparoscopic mesh repair of inguinal hernia. N Engl J Med 350(18):1819-1827

63. Lau H, Patil NG, Yuen WK (2002) Learning curve for unilateral endoscopic totally extraperitoneal (TEP) inguinal hernioplasty. Surg Endosc 16:1724-1728. https://doi.org/10.1007/ s00464-001-8298-0

64. Aeberhard P, Klaiber C, Meyenberg A (1999) Prospective audit of laparoscopic totally extraperitoneal inguinal hernia repair: a multicenter study of the Swiss Association for Laparoscopic and Thoracoscopic Surgery (SALTC). Surg Endosc. 13:1115-1120. https://doi.org/10.1007/s004649901185

Publisher's Note Springer Nature remains neutral with regard to jurisdictional claims in published maps and institutional affiliations. 